\title{
Experimental and theoretical study of 1, 4-naphthoquinone based dye in dye-sensitized solar cells using ZnO photoanode
}

\author{
Dnyaneshwar Shinde ${ }^{1}$, Popat Tambade $^{1, *}$, Habib Pathan $^{2}$, Kisan Gadave $^{1}$ \\ ${ }^{1}$ Prof. Ramkrishna More Arts, Commerce and Science College, Akurdi, Pune, India \\ ${ }^{2}$ Department of Physics, Savitribai Phule Pune University, Pune, India
}

\begin{abstract}
A dye-sensitized solar cell (DSSC) was assembled using a dye 4-(3-chloro-1, 4-dioxo-1, 4-dihydronaphthalen-2-ylamino) benzoic acid with $\mathrm{ZnO}$ as a photoanode. It was synthesized using 2, 3-dichloro 1, 4-naphthoquinone and p-amino benzoic acid. The spectral features of the dye were analyzed in ethanol using experimental and computational methods. The theoretical investigations revealed that the synthesized dye may act as a sensitizer in DSSCs. The photoelectrochemical performance was tested under direct sunlight using a sandwich type DSSC. The photovoltaic data of the dye adsorbed on $\mathrm{ZnO}$ films indicated the power conversion efficiency of $1.07 \%$ under sunlight with a light intensity of $39 \mathrm{~mW} \cdot \mathrm{cm}^{-2}$.
\end{abstract}

Keywords: dye-sensitized solar cell; ZnO; naphthoquinone; density functional theory; TDDFT

\section{Introduction}

Dye-sensitized solar cells (DSSCs) based on metal oxide semiconductors, such as titanium dioxide $\left(\mathrm{TiO}_{2}\right)$, zinc oxide $(\mathrm{ZnO})$, and tin oxide, and coordination complexes or organic dyes have been widely studied. DSSCs may provide a potential alternative to silicon solar cells because of their cost effectiveness and ease of fabrication [1-6]. The DSSC is a photoelectrochemical system that incorporates a porous-structured metal oxide semiconductor film with adsorbed dye molecules as the photoanode. A platinized or carbon or graphenecoated fluorine-doped tin oxide (FTO) glass acts as a counter electrode. A liquid electrolyte, such as the $\mathrm{I}^{-} / \mathrm{I}_{3}^{-}$redox couple, is used to connect electrically the two electrodes [7]. Factors such as particle size, shape, porosity and film thickness of metal oxides, dye, electrolyte composition, and separation between electrodes are crucial in the performance of DSSCs. The interfacial properties between each component of the DSSCs play a vital role in efficiency. A nanostructured porous oxide material used in DSSCs provides a large surface area for dye adsorption, which maximizes light

*E-mail: pstam3@rediffmail.com harvesting [8-10]. DSSCs using $\mathrm{TiO}_{2}$ nanoparticles in photoanodes have been widely studied because of their remarkable chemical, electrical, and optical properties. Energy conversion efficiencies, as high as $11 \%$, have been reported for DSSCbased $\mathrm{TiO}_{2}$ nanoparticles. The most suitable dyes in DSSCs are based on ruthenium (II) bipyridyl compounds. These dyes have a large absorption coefficient in the visible region of the solar spectrum. They have good adsorption properties, excellent stability, as well as efficient electron injection [11-14]. However, the dyes based on ruthenium compounds are relatively expensive, and their availability is limited. Alternatives to these dyes, such as organic dyes having similar properties, are being researched [15-21]. Natural pigments are widely used as photosensitizers in DSSCs to study photoelectrochemical properties with $\mathrm{TiO}_{2}$ as well as $\mathrm{ZnO}$ photoelectrodes. Carotenoids, chlorophyll, cyanidin, and delphinidin as well as cyanine and nasunin have been studied extensively. Although natural pigments are promising sensitizers in DSSCs, the efficiencies obtained with these pigments are considerably lower than those obtained with synthetic dyes [22-28].

$\mathrm{ZnO}$ has energy levels similar to those of $\mathrm{TiO}_{2}$. It has much higher carrier mobility, which is 
more favorable for the collection of photoinduced electrons [7]. Moreover, $\mathrm{ZnO}$ can be experimentally grown in a wide variety of nanostructures, such as nanoparticles, nanowires or nanorods, nanotubes, and nanobelts, and these may be used in DSSCs [29-36]. Hence, $\mathrm{ZnO}$ is a promising alternative to $\mathrm{TiO}_{2}$ for the fabrication of photoanodes in DSSCs.

The prediction of molecular energy levels and electronic transitions of dye molecules is a vital part in designing DSSCs. The density functional theory (DFT) and time-dependent density functional theory (TDDFT) have been used extensively to theoretically study the electronic and charge transfer properties of dye molecules [19, 37].

In the present work, we synthesized an organic dye using a simple chemical reaction. The dye was examined computationally using DFT and TDDFT, to gain insight into the energy levels and electronic structure of the dye molecule. The groundstate geometries, electronic structures, and UV-Vis absorption spectra were obtained using computational methods. The synthesized dye was characterized experimentally by using the UV-Vis absorption spectrum. The photoelectrochemical properties of the DSSC using this dye as a sensitizer with $\mathrm{ZnO}$ as the photoanode were investigated.

\section{Materials and methods}

\subsection{Synthesis of $\mathrm{ZnO}$ nanoparticles}

$\mathrm{ZnO}$ was synthesized, using a known method, from zinc oxalate as a precursor $[38,39]$. The precursor was synthesized by dry grinding zinc acetate and oxalic acid in 1:1 proportion. The reaction mixture was ground until the smell of acetic acid disappeared completely and then dried in an oven at $120^{\circ} \mathrm{C}$ for $1 \mathrm{~h}$. The dried precursor was ignited in a silica crucible in an open atmosphere on a Bunsen burner and then annealed in a muffle furnace at $500{ }^{\circ} \mathrm{C}$ for $90 \mathrm{~min}$. The annealed $\mathrm{ZnO}$ powder was subjected to ball milling for further grinding. The synthesized $\mathrm{ZnO}$ was characterized using different physicochemical methods. The surface morphology of $\mathrm{ZnO}$ powder was observed using a scanning electron microscopy (SEM). The structural properties of the particles were studied using the X-ray diffraction (XRD) method. The band gap of $\mathrm{ZnO}$ particles was estimated by using ultraviolet diffuse reflectance spectroscopy (UV-DRS) spectra.

\subsection{Synthesis of dye}

The dye was synthesized using a grinding method. The reaction between 2, 3-dichloro 1, 4-naphthoquinone (1 M) and para-amino benzoic acid (1 M) was carried out with addition of $\mathrm{NaOH}(1 \mathrm{M})$ by grinding together for $10 \mathrm{~min}-$ utes. The resultant product was washed with water and dried under vacuum. The resultant product was 4-(3-chloro-1, 4-dioxo 1, 4-dihydronaphthalen-2ylamino) benzoic acid $\left(\mathrm{C}_{17} \mathrm{H}_{10} \mathrm{ClNO}_{4}\right)$ with molecular weight $327.719 \mathrm{~g}$. The product was a reddishbrown solid [40, 41]. The product was recrystallized and analyzed through TLC to detect the presence of by-products. The reaction is presented in equation 1 :

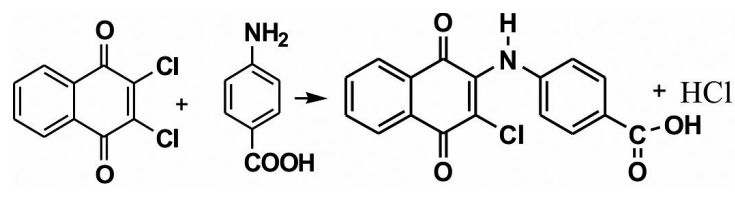

$$
\mathrm{HCl}+\mathrm{NaOH} \rightarrow \mathrm{NaCl}+\mathrm{H}_{2} \mathrm{O}
$$

The synthesized dye is a naphthoquinone derivative and will hereafter be referred to as DNPABA dye. The reagent para aminobenzoic acid was intentionally selected so that the dye consisted of requisite carboxyl groups that can bind easily to the surface of the $\mathrm{ZnO}$ nanoparticles and impart a red color to the dye. The DNPABA dye so prepared is water insoluble.

\subsection{Computational study}

The knowledge of the highest occupied molecular orbital (HOMO) and lowest unoccupied molecular orbital (LUMO) energy levels of dye molecules facilitates the understanding of photo conversion efficiency in DSSCs. It is also useful for the synthesis of new, efficient dye molecules for 
DSSCs [19, 42, 43]. The molecular geometries for the ground state of the dye molecule were first optimized in vacuum without symmetry constraints at B3LYP functional and 6-311++G (d, p) basis set. The TDDFT calculations at the PBE0 functional and $6-311++\mathrm{G}(\mathrm{d}, \mathrm{p})$ basis set were used to simulate the UV-Vis spectrum of the dye in vacuum as well as in the solvent. Ten lowest singlet vertical excitation energies and oscillator strengths were used for this prediction. The polarizable continuum model was used to study the solvation effect in methanol. All chemical quantum calculations were performed using the Firefly program package [44].

\subsection{Preparation of photoanode}

The $\mathrm{ZnO}$ nanoparticle paste was prepared by dispersing $\mathrm{ZnO}$ nanoparticles in ethanol, ethyl cellulose, acetyl acetone, and alpha terpineol in requisite weight proportions and it was continuously stirred for $1 \mathrm{~h}$ for proper mixing. The FTO (16 $\Omega / \square$ ) substrate was first cleaned using a detergent solution in an ultrasonic bath for $20 \mathrm{~min}$, rinsed with water and ethanol, and dried. The $\mathrm{ZnO}$ paste was deposited on the FTO conductive glass surface by using the doctor-blade technique and a $\mathrm{ZnO}$ film of approximately $15 \mu \mathrm{m}$ thickness and an area of $0.25 \mathrm{~cm}^{2}$ was obtained. The coated FTO substrate was then heated up to $450{ }^{\circ} \mathrm{C}$ using a slow heating program followed by annealing in air at the same temperature for $60 \mathrm{~min}$. This annealing process ensured that all organic solvents, binders, and fillers present in the $\mathrm{ZnO}$ paste burned away, leaving behind only a mesoporous structure of interconnected $\mathrm{ZnO}$ particles $[30,36]$. The annealed $\mathrm{ZnO}$ electrodes were soaked in $0.05 \%$ DNPABA dye in ethanol solution $(\mathrm{pH} 7)$ for $3 \mathrm{~h}$ at room temperature. Following dye adsorption, the photoanodes were thoroughly rinsed with ethanol and stored in a desiccator in the dark at room temperature for $24 \mathrm{~h}$.

\subsection{Counter electrode}

For the preparation of a counter electrode, finely powdered graphite was prepared from HB pencil lead by grinding. Then, the properly cleaned FTO glass surface was rubbed with a graphite powder.
A thin and uniform film of graphite was observed on the FTO plate. The carbonaceous counter electrodes that exhibit numerous advantages, such as high electronic conductivity, corrosion resistance toward reduction, and low cost, may act as substitutes for platinum electrodes $[45,46]$.

\subsection{Fabrication of DSSC}

The sandwich of DSSC of $0.25 \mathrm{~cm}^{2}$ was assembled using a photoanode and cathode. The cell was filled with polyiodide $(0.5 \mathrm{M} \mathrm{KI}+0.05 \mathrm{M}$ $\mathrm{I}_{2}$ ) and sealed from all sides. The photoanode was covered using an external shadow mask of open area of $0.25 \mathrm{~cm}^{2}$ to avoid excessive exposure of photoanode to sunlight [14-16]. Current-voltage curves were measured in sunlight at Pune (India, $18.52^{\circ} \mathrm{N}, 73.86^{\circ} \mathrm{E}$ ), arranging the cell to obtain the highest possible value for the short-circuit current density.

The photovoltaic performance of DSSC is assessed using current-voltage (I-V) measurements when the cell is irradiated under direct sunlight. The photovoltaic parameters of DSSC are open circuit potential $\left(\mathrm{V}_{\mathrm{OC}}\right)$, short-circuit current $\left(\mathrm{I}_{\mathrm{SC}}\right)$, fill factor $(\mathrm{FF})$, and efficiency $(\eta)$.

The overall power conversion efficiency $\eta$ can be calculated according to the following formula:

$$
\eta=\frac{F F \times V_{O C} \times I_{S C}}{P_{i n}}
$$

The fill factor (FF) is defined as follows:

$$
F F=\frac{V_{m} \times I_{m}}{V_{O C} \times I_{S C}}
$$

where $\mathrm{P}_{\text {in }}$ is the input power density (i.e. the intensity of incident light, in $\mathrm{mW} \cdot \mathrm{cm}^{-2}$ ), $\mathrm{V}_{\mathrm{OC}}$ is the open-circuit voltage $(\mathrm{mV}), \mathrm{I}_{\mathrm{SC}}$ is the short-circuit current density $\left(\mathrm{mA} \cdot \mathrm{cm}^{-2}\right)$, and $\mathrm{V}_{\mathrm{m}}$ and $\mathrm{I}_{\mathrm{m}}$ are the voltage and current at maximum power output, respectively [47].

\section{Results and discussion}

\subsection{Purity of $\mathbf{Z n O}$}

The purity of $\mathrm{ZnO}$ was determined by chemical methods where $\mathrm{Zn}(\mathrm{II})$ content was analyzed 
using complexometric titration. It agreed well with the molecular formula of $\mathrm{ZnO}$.

\subsection{Structural studies on $\mathrm{ZnO}$}

The prepared $\mathrm{ZnO}$ nanoparticles were characterized for their nanostructural properties. The $\mathrm{X}$-ray diffraction (XRD) pattern was recorded using an X-ray diffractometer (MD-10) with $\mathrm{CuK} \alpha$ radiation of wavelength $\lambda=1.5406 \AA$ in the scan range $2 \theta=20^{\circ}$ to $80^{\circ}$. The XRD spectrum is depicted in Fig. 1. The diffraction peaks observed at $2 \theta$ values of $31.79^{\circ}, 34.44^{\circ}, 36.27^{\circ}, 47.56^{\circ}, 56.61^{\circ}$, $62.87^{\circ}, 66.39^{\circ}, 67.96^{\circ}$, and $69.09^{\circ}$, could be indexed to different planes of crystalline $\mathrm{ZnO}$ with wurtzite structure as illustrated in Fig. 1 (JSPDF File No. 79-2205). The average particle size, calculated using the Debye-Scherrer equation, is $48 \mathrm{~nm}$.

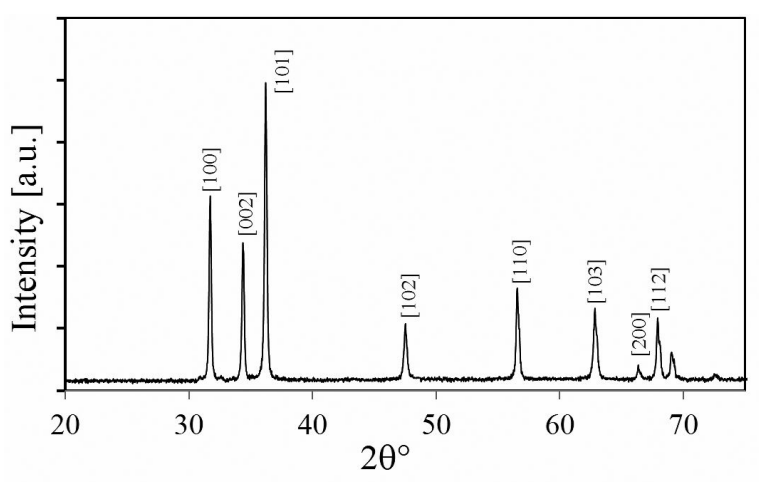

Fig. 1. XRD pattern of $\mathrm{ZnO}$ powder.

\subsection{Surface morphology studies on $\mathrm{ZnO}$}

The morphology of the $\mathrm{ZnO}$ powder is presented as a SEM image in Fig. 2. It is seen that the sample has a relatively uniform particle diameter. This uniformity improves the photoelectrochemical properties of the corresponding film electrode. $\mathrm{ZnO}$ powder shows grains with a large diameter of $200 \mathrm{~nm}$ to $500 \mathrm{~nm}$.

\subsection{Optical properties of $\mathrm{ZnO}$}

The UV-DRS spectra in absorbance mode of both $\mathrm{ZnO}$ and dye sensitized $\mathrm{ZnO}$ were recorded (Fig. 3). The difference between the two curves is

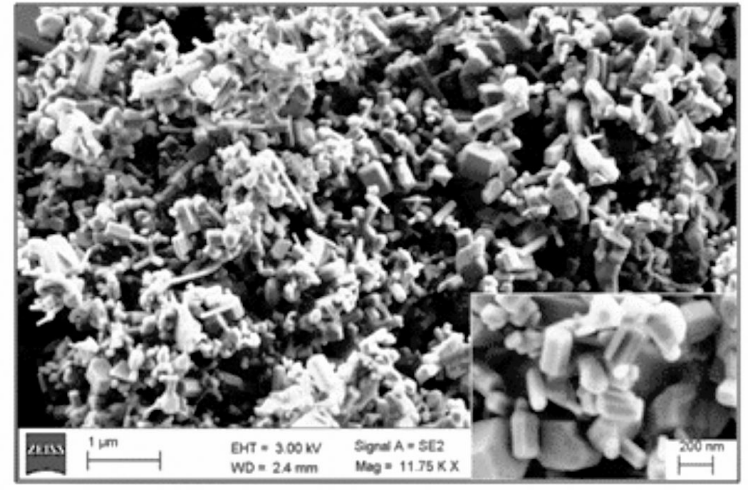

Fig. 2. SEM micrograph of $\mathrm{ZnO}$ powder.

due to light absorbance by the dye. The spectra indicate that both $\mathrm{ZnO}$ and sensitized $\mathrm{ZnO}$ absorb UV light below $400 \mathrm{~nm}$, whereas only the latter absorbs light in the visible region.

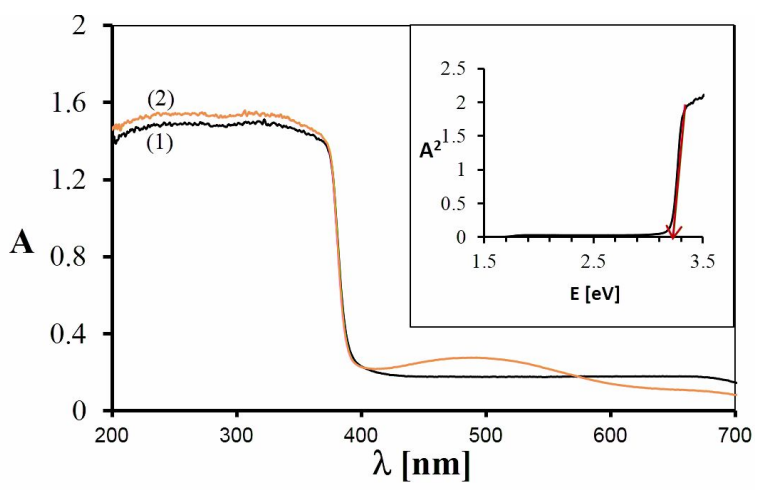

Fig. 3. Absorbance (A) vs. wavelength $(\lambda)$ spectra of (1) $\mathrm{ZnO}$ and (2) dye sensitized $\mathrm{ZnO}$. Inset $\mathrm{A}^{2}$ versus $\mathrm{E}(\mathrm{eV})$.

The maximum of absorbance in the visible region is at $492 \mathrm{~nm}$. The broadening and redshift of $\lambda_{\max }$ of absorption spectra is observed for the DNPABA dye adsorbed on $\mathrm{ZnO}$, suggesting that a strong interaction has occurred between the dye molecules and the surface of the $\mathrm{ZnO}$ nanoparticles. The delocalized $\pi^{*}$ state of the dye injects effectively into the conduction band of $\mathrm{ZnO}[25,48]$. This also implies that terminal carboxylic group and carbonyl group of the dye may form a covalent bond with metallic sites in solid $\mathrm{ZnO}$. The band gap of $\mathrm{ZnO}$ is obtained by plotting a graph of $\mathrm{A}^{2} \mathrm{vs.} \mathrm{hv}$ (Fig. 3). It was found to be $3.2 \mathrm{eV}$ for $\mathrm{ZnO}[17,29]$. 


\subsection{Theoretical and experimental UV-Vis absorption spectra of the dye}

The experimental absorption spectrum and band gap energies of the DNPABA dye molecules were determined using a UV-Vis spectrophotometer (Systronics 2202 model). The absorption spectrum of the dye molecule is depicted in Fig. 4. The dye shows a broad absorption band in the visible region centered at $482 \mathrm{~nm}$. The spectrum also shows two more absorption bands at $339 \mathrm{~nm}$ and $282 \mathrm{~nm}$ in the UV region. The energy gap between HOMO and LUMO orbitals of the dye was calculated on the basis of the lowest energy absorption band, which is $2.73 \mathrm{eV}$. The ten lowest singlet

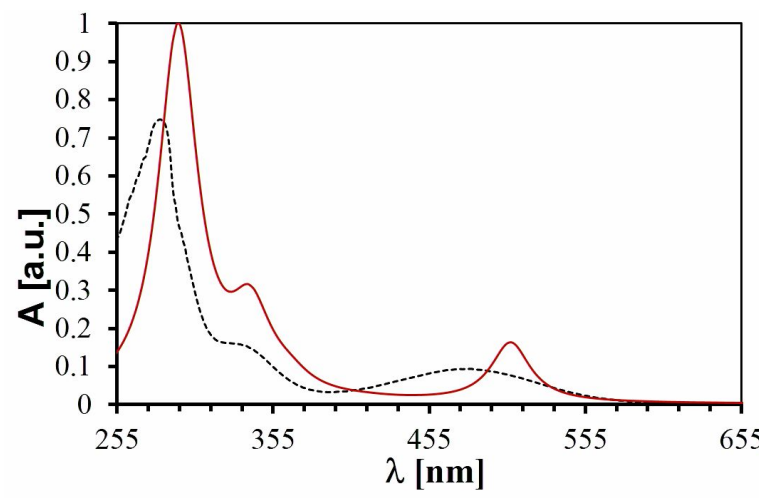

Fig. 4. UV-absorption spectra experimental (dotted) and calculated (solid) of the DNPABA dye in arbitrary units.

vertical excitation energies and oscillator strengths from the TDDFT calculations, determined on the basis of the optimized ground state geometry, were used to predict the UV-Vis spectrum of the dye in the vacuum and solvent phase. These were transformed using the Gabeditt-248 program into simulated spectra using Gaussian functions [49]. The experimental and simulated UV-Vis spectra with ethanol solvent are illustrated in Fig. 4. The dye molecule, to act as an efficient photosensitizer in DSSCs, should intensely absorb light in the visible region $(400 \mathrm{~nm}$ to $700 \mathrm{~nm})$ of the solar spectrum. The simulated absorption spectra of the dye is clearly divided into two regions with two peaks in the UV region and one peak in the visible region. The absorption wavelengths of DNPABA are listed in Table 1 . The first optically allowed electronic transition of the dye was predicted to populate the $\mathrm{HOMO} \rightarrow$ LUMO transitions with $\lambda_{\max }$ at $508 \mathrm{~nm}$ in vacuum and $511 \mathrm{~nm}$ in the solvent phase. This absorption in the visible region is caused by the transfer of electrons from a donor to an acceptor unit of the dye molecule [50].

The experimentally measured UV-Vis parameters in ethanol and the calculated UV-Vis parameters in vacuum as well as ethanol for DNPABA are listed in Table 1.

According to Satheshkumar et al. [40] 2, 3-dichloronaphthoquinone exhibits an absorbance peak at $341 \mathrm{~nm}$ corresponding to $\pi \rightarrow \pi^{*}$ transition. When it is para-substituted by aniline, a new broad peak centered at $479 \mathrm{~nm}$ is observed, which shows intramolecular charge transfer transitions between $\mathrm{N}$-atom and quinine. It is observed here experimentally that the addition of para-amino benzoic acid to 2, 3-dichloro, 1, 4-naphthoquinone caused a new peak centered at $482 \mathrm{~nm}$.

\subsection{HOMO-LUMO analysis}

Fig. 5 illustrates the electron density distributions of the frontier molecular orbitals (HOMO and LUMO) for the dye sensitizer that were obtained using the B3LYP/6-311++G $(d, p)$ level of theory. The electron densities of HOMO orbitals are delocalized over the $\pi$-system with the highest electron density centered on and close to the nitrogen atom. The LUMO orbital is delocalized over the naphthoquinone subunit, which indicates a good charge separated state between the two sub-units of the molecule $[38,42]$.

The calculated absolute energies of HOMO and LUMO are $-6.541 \mathrm{eV}$ and $-3.782 \mathrm{eV}$, respectively, with HOMO-LUMO gap of $2.759 \mathrm{eV}$. The HOMO and LUMO levels of a dye used in a DSSC must be suitably placed with respect to the conduction band $(\mathrm{CB})$ edge energy level $\left(\mathrm{E}_{\mathrm{CB}}\right)$ of the $\mathrm{ZnO}$ and the redox potential of electrolytes for efficient charge separation and dye regeneration. The HOMO level of the dye must be sufficiently more positive than the redox potential of the electrolyte and the LUMO level must be sufficiently 
Table 1. The experimental and calculated UV-Vis parameters of DNPABA.

\begin{tabular}{ccccc}
\hline \multirow{2}{*}{ Exp. $\lambda[\mathrm{nm}$ ] in ethanol } & \multirow{2}{*}{ Transition } & \multicolumn{3}{c}{ The calculated UV-Vis parameter in vacuum/ethanol } \\
\cline { 3 - 5 } & & $\lambda[\mathrm{nm}]$ & Excitation energy [eV] & $\mathrm{f}$ (oscillator strength) \\
\hline \hline 482 & $\mathrm{n} \rightarrow \pi^{*}$ & $508 / 511$ & $2.43 / 2.42$ & $0.0929 / 0.1104$ \\
- & & $372 / 380$ & $3.34 / 3.25$ & $0.0142 / 0.01017$ \\
339 & $\pi \rightarrow \pi^{*}$ & $331 / 341$ & $3.74 / 3.63$ & $0.0873 / 0.08077$ \\
- & & $295 / 294$ & $4.2 / 4.20$ & $0.4522 / 0.5914$ \\
282 & $\mathrm{n} \rightarrow \sigma^{*}$ & $287 / 293$ & $4.32 / 4.22$ & $0.3319 / 0.1469$ \\
\hline
\end{tabular}

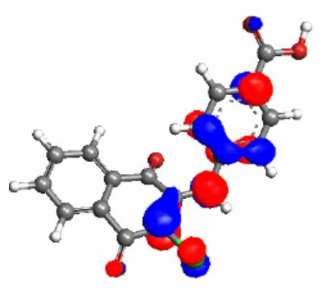

(a) $\mathrm{HOMO}$

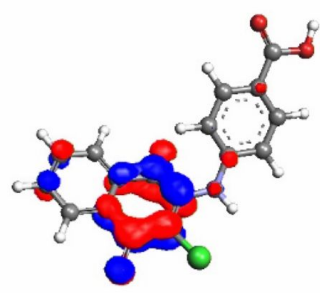

(b) LUMO
Fig. 5. Molecular orbital plots of DNPABA. The wave functions are plotted at an absolute isovalue of $0.02 \mathrm{au}$ in red and blue for the opposite phases, respectively.

more negative than the $\mathrm{E}_{\mathrm{CB}}$ of $\mathrm{ZnO}[19,43]$. Fig. 6 depicts the band diagram with HOMO/LUMO levels of DNPABA, CB and $\mathrm{VB}$ of $\mathrm{ZnO}$, the work function of FTO, and the reduction potential of the $\mathrm{I}_{3}^{-} / \mathrm{I}^{-}$electrolyte.

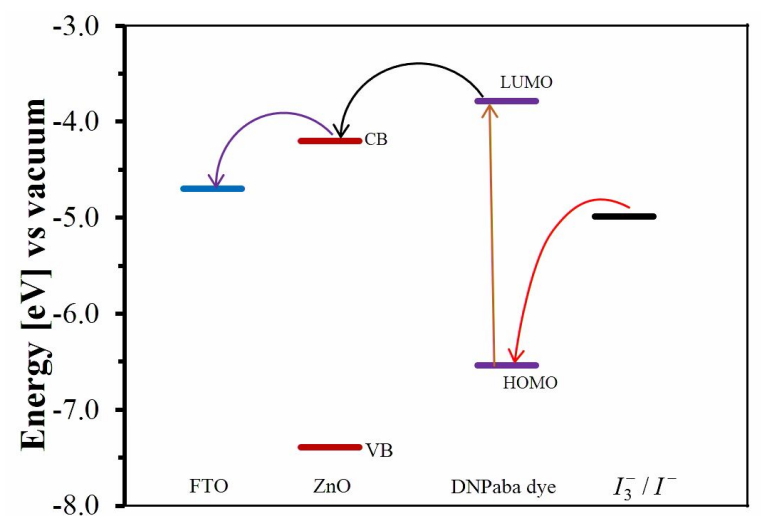

Fig. 6. Energy levels.

The LUMO level of DNPABA positioned at $-3.782 \mathrm{eV}$, is sufficiently higher than the $\mathrm{CB}$ of
$\mathrm{ZnO}(-4.2 \mathrm{eV})$. The LUMO levels are sufficiently more negative than the $\mathrm{E}_{\mathrm{CB}}$ with a driving force of $-0.408 \mathrm{eV}$ to inject electrons from the excited dye to the $\mathrm{CB}$ of $\mathrm{ZnO}$. The HOMO level located at $-6.541 \mathrm{eV}$ is more positive than the redox potential of $\mathrm{I}^{-} / \mathrm{I}_{3}^{-}(-4.99 \mathrm{eV})$, and the driving force needed for dye regeneration is $1.55 \mathrm{eV}$; therefore, the resultant dye ${ }^{+}$can be reduced by $\mathrm{I}^{-}$in the electrolyte. This proves that the energy level requirement is fulfilled by the dye for fabricating an organic solar cell using the DNPABA dye. The relatively large energy gaps between the LUMO and the $\mathrm{E}_{\mathrm{CB}}$ values could improve the voltage, and consequently, the total efficiency [51-53].

\subsection{Photoelectrochemical characteristics of ZnO DSSCs}

Photovoltaic tests on assembled DSSCs using the DNPABA dye were performed using currentvoltage (J-V) curves in natural sunlight. The performance of the DNPABA dye as sensitizer in DSSCs was evaluated using short circuit current density, $\mathrm{V}_{\mathrm{oc}}, \mathrm{FF}$, and energy conversion efficiency $\eta$. Fig. 7 shows the J-V characteristic of ZnO DSSCs with $\mathrm{ZnO}$ film at a thickness of $15 \mu \mathrm{m}$.

The photoelectrochemical parameters at different intensities of sunlight are listed in Table 2.

The cells with $\mathrm{ZnO}$ working electrodes and DNPABA dye as a sensitizer demonstrated the best photovoltaic performance compared with the cells with $\mathrm{ZnO}$ working electrodes and natural dyes as a sensitizer [13, 20, 21]. Obviously, synthetic dyes have higher sensitization activity and stability than natural dyes $[10,14]$. The natural dyes used as 


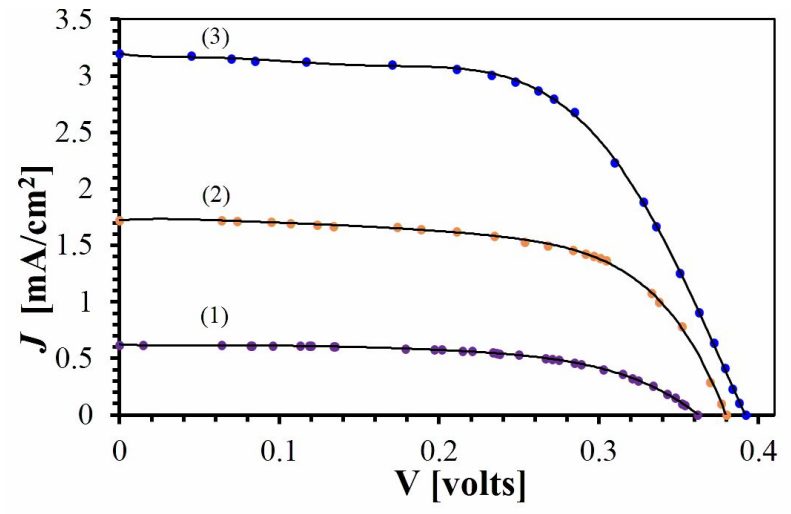

Fig. 7. Photocurrent-voltage characteristics of DSSCs in sunlight with $\mathrm{P}_{\text {in }}$ (1) $10.4 \mathrm{~mW} / \mathrm{cm}^{2}$ and (2) $39 \mathrm{~mW} / \mathrm{cm}^{2}$ (3) $100 \mathrm{~mW} / \mathrm{cm}^{2}$.

Table 2. Photovoltaic parameters of DNPABA dyesensitized nanocrystalline $\mathrm{ZnO}$ solar cells at different intensities.

\begin{tabular}{cccccc}
\hline $\begin{array}{c}\mathrm{P}_{\text {in }} \\
{\left[\mathrm{mW} / \mathrm{cm}^{2}\right]}\end{array}$ & $\begin{array}{c}\mathrm{V}_{\text {oc }} \\
{[\mathrm{V}]}\end{array}$ & $\begin{array}{c}\mathrm{I}_{\mathrm{sc}} \\
{\left[\mathrm{mA} / \mathrm{cm}^{2}\right]}\end{array}$ & $\begin{array}{c}\mathrm{P}_{\max } \\
{\left[\mu \mathrm{W} / \mathrm{cm}^{2}\right]}\end{array}$ & $\begin{array}{c}\text { Fill } \\
\text { factor }\end{array}$ & $\begin{array}{c}\eta \\
{[\%]}\end{array}$ \\
\hline \hline 10.4 & 0.362 & 0.621 & 133.5 & 0.59 & 1.28 \\
12.5 & 0.372 & 0.633 & 140.0 & 0.59 & 1.13 \\
22 & 0.373 & 0.965 & 231.1 & 0.64 & 1.05 \\
39 & 0.380 & 1.72 & 418.3 & 0.64 & 1.07 \\
100 & 0.392 & 3.196 & 746.86 & 0.60 & 0.75 \\
\hline
\end{tabular}

sensitizers in DSSCs provide very low efficiencies because of the absence of specific functional attachment groups and low absorption in the visible region of the solar spectrum [54-58]. Zhang et al. [59] synthesized three synthetic dyes and studied them by using ${\mathrm{a} i \mathrm{O}_{2}}_{2}$ photoanode and observed efficiencies as high as $7.6 \%$, which are higher than those of natural dyes. Khadtare et al. [50] studied DSSCs with 1, 4-naphthoquinone-based Lawson dye using a $\mathrm{ZnO}$ photoanode and observed an efficiency $0.56 \%$ at $100 \mathrm{~mW} / \mathrm{cm}^{2}$ input power. The present study revealed that the derivatives of 2 , 3-dichloro 1, 4-naphthoquinone can provide the basis for the design of novel organic dyes in DSSC applications to enhance their efficiency. In future, authors have planned to study different derivatives of 1, 4-naphthoquinone to further enhance the performance of the device.

\subsection{Electrochemical impedance spec- troscopy studies}

To investigate the internal resistance of DNPABA-based DSSC, Electrochemical Impedance Spectroscopy (EIS) was carried out at $-0.4 \mathrm{~V}$ bias in the dark using Vertex (IVIUM Technologies). The frequency range chosen for the measurement ranged from $100 \mathrm{mHz}$ to $1 \mathrm{MHz}$ with an AC amplitude of $10 \mathrm{mV}$. Fig. 8 illustrates the typical Nyquist plot of the impedance of the data under dark condition of DSSC.

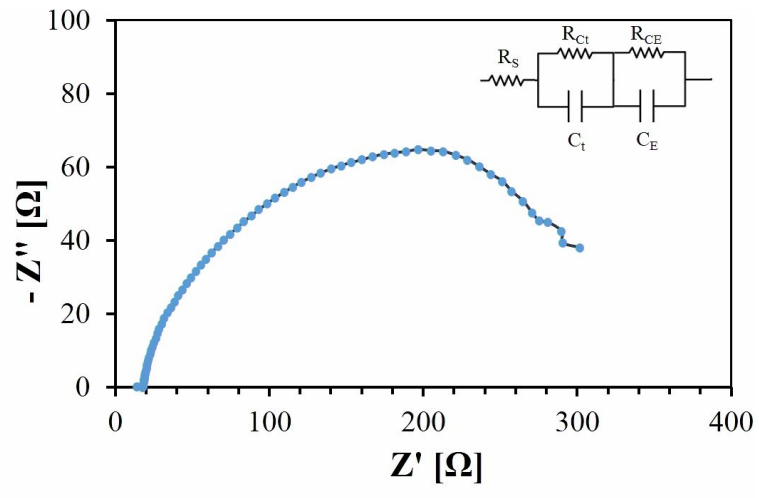

Fig. 8. The Nyquist plot of the impedance characteristics between $\mathrm{Z}_{\text {real }}$ and $\mathrm{Z}_{\text {imaginary }}$ of $\mathrm{ZnO}$ photoanode DSSC.

The observed charge transfer resistance $\mathrm{R}_{\mathrm{ct}}$ of the device is $81.6 \Omega$, the chemical capacitance $C_{\mu}$ is $2.2 \times 10^{-4} \mathrm{~F}$, and the electron lifetime is $14.2 \mathrm{~ms}$. The effective diffusion coefficient has been found as $5.69 \times 10^{-4} \mathrm{~cm}^{2} / \mathrm{s}$. From the EIS data, the electron diffusion length $\mathrm{L}_{\mathrm{n}}$ is about $28.41 \mu \mathrm{m}$ [60].

\section{Conclusions}

The spectral characteristics of an organic dye, used as a photosensitizer to assemble DSSCs, were studied using experimental and computational approaches. The synthesized dye exhibits absorption at $482 \mathrm{~nm}$ and can be used as a sensitizer in dye-sensitized solar cells. The simulated absorption spectrum of the DNPABA dye in ethanol using the TDDFT/PBE0/6-311+G (d, p) calculation is in good agreement with the experimental values. The analyses of molecular orbitals showed 
that the charge densities of the HOMO and LUMO are spatially separated on the molecule. Hence, the dye is a charge transfer molecule and shows the dominance of $\pi \rightarrow \pi^{*}$ transitions. Theoretical calculations demonstrate that singlet-singlet excited state energy levels of a DNPABA dye molecule align well with the conduction band edge of $\mathrm{ZnO}$ nanoparticles. $\mathrm{ZnO}$ nanoparticles were prepared and then applied as working electrodes in a solar cell sensitized with the synthesized dye. Although the efficiencies obtained are less than those of commercial solar cells, the study shows the potential of the synthesized dye for the use as sensitizer in DSSC, and may be a proposal for more focused research in this direction. The results are encouraging and may boost additional research for new dyes to optimize the photo conversion efficiencies of DSSCs.

\section{References}

[1] O’Regan B., Grätzel M.A., Nature, 353 (1991), 737.

[2] Kay A., Grätzel M., J. Phys. Chem., 97 (1993), 6272.

[3] Roy M.S., Balraju P., Kumar M., Sharma G.D., Sol. Energ. Mat. Sol. C., 92 (2008), 909.

[4] Chauhan R., Kumar A., Chaudhary R.P., J. SolGel Sci. Technol., 63 (2012), 546.

[5] Basu K., Benetti D., ZhaO H., Jin L., Vetrone F., Vomiero A., Rosei F., Sci. Rep., 6 (2016), 23312, DOI: 10.1038/serp23312.

[6] Shang G., Wu J., Huang M., Lin J., Lan Z., Huang Y., Fan L., J. Phys. Chem. C, 116 (2012), 20140.

[7] Elsayed E.M., Shalan A.E., Rashad M.M., J. Mater. Sci. Mater. Electron., 25 (2014), 3412.

[8] Katoh R., Huijser A., Hara K., SaveniJe T.J., Siebbeles L., J. Phys. Chem. C, 111 (2007), 10741.

[9] Park K., Zhang Q., Myers D., CaO G., ACS Appl. Mater. Interfaces, 5 (2013), 1044.

[10] Chou T.P., Zhang Q., Russo B., Fryxell G.E., CaO G., J. Phys. Chem. C, 111 (2007), 6296.

[11] Chiba Y., Islam A., Watanabe Y., Komiya R., Koide N., Han L., Jpn. J. Appl. Phys., 45 (2006), L638.

[12] Wang Z., KaWAUChi H., Kashima T., Arakawa H., Coord. Chem. Rev., 248 (2004), 1381.

[13] Hug H., Bader M., Mair P., Glatzel T., Appl. Energ., 115 (2014), 216.

[14] Calogero G., Di Marco G., Sol. Energ. Mat. Sol. C., 92 (2008), 1341.
[15] Tripathi M., Upadhyay R., Pandey A., Appl. Sol. Energ., 49 (2013), 54.

[16] Ranjitha S., Aroulmoji V., Mohr T., AnBaras an P.M., Rajarajan G., Acta Phys. Pol. A, 126 (2014), 833.

[17] Suri P., Panwar M., Mehra R.M., Mater. Sci.Poland, 25 (2007), 137.

[18] KIM S., LeE J.K., Kang S.O., Ko J., YUM J.H., Fantacci S., de Angelis F., Censo Di D., NaZeEruddin M.K., Grätzel M., J. Am. Chem. Soc., 128 (2006), 16701.

[19] IRFAN A., Optik, 125 (2014), 4825.

[20] Batniji A.Y., Morjan R., AbDel-Latif M.S., EL-Agez T.M., TAYA S.A., EL-GHAMri H.S., Turk. J. Phys., 38 (2014), 86.

[21] El-Agez T.M., TAYA S.A., Elrefi K.S., ABdelLATIF M.S., Opt. Appl., 44 (2014), 345.

[22] GomeZ-OrTiz N.M, VAZQUEZ-MALDONADO I.A, Perez-Espadas A.R., Mena-Rejon G.J., Azamar-Barrio J.A, Oskam G.G, Sol. Energ. Mat. Sol. C., 94 (2010), 40.

[23] Zhou H., Wu L., Gao Y., Ma T., J. Photoch. Photobiol. A, 219 (2011), 188.

[24] Wongcharee K., Meeyooa V., Chavadej S., Sol. Energ. Mat. Sol. C., 91 (2007), 566.

[25] Yamazaki E., Murayama M., Nishikawa N., Hashimoto N., Shoyama M., Kurita O., Sol. Energy, 81 (2007), 512.

[26] Hao S., Wu J., Huang Y., Lin J., Sol. Energy, 80 (2006), 209.

[27] El-Ghamri H.S., El-Agez T.M., TAYA S.A., Abdel-Latif M.S., BatniJi A.Y., Mater. Sci.Poland, 32 (2014), 547.

[28] TAYA S.A., El-AgEZ T.M., ABdel-Latif M.S., EL-GHAMri H.S., BATNIJI A.Y., EL-SHEIKH I.R., Int. J. Renew. Energy Res., 4 (2014), 384.

[29] Teesetsopon P., Kumar S., Dutta J., Int. J. Electrochem. Sc., 7 (2012), 4988.

[30] Zhang Q., Dandeneau C.S., Zhou X., CaO G., Adv. Mater., 21 (2009), 4087.

[31] Lai M.H., Lee M.W., Wang G., Tai M.F., Int. J. Electrochem. Sc., 6 (2011), 2122.

[32] Jung M., Chu M., J. Mater. Chem. C, 2 (2014), 6675.

[33] BAXter J.B., WAlKer A.M., VAN OMmering K., AYDIL E.S., Nanotechnology, 17 (2006), S304.

[34] Ranjusha R., Lekha P., Subramanian K.R.V., NAIR SHANTIKUMAR V., BALAKRISHNAN A., $J$. Mater. Sci. Technol., 27 (2011), 961.

[35] Han J., Fan F., Xu C., Lin S., Wei M., Duan X., WANG Z.L., Nanotechnology, 21 (2010), 405203.

[36] Hongsith N., Choopun S., Chiang Mai J. Sci., 37 (2010), 48

[37] Nazeeruddin M., De Angelis F., Fantacci S., SElloni A., Viscardi G., Liska P., Ito S., TAKeru B., Grätzel M., J. Am. Chem. Soc., 127 (2005), 16835.

[38] Patil A.B., Patil K.R., Pardeshi S.K., J. Solid State Chem., 184 (2011), 3273. 
[39] Pawar R.A., Shinde D.R., Tambade P.S., Desalin. Water Treat., 57 (2016), 16514.

[40] Satheshiumar A., Elango K.P., Spectrochim. Acta A, 98 (2012), 378.

[41] Mital A., Sonawane M., Bindal S., Mahlavat S., Negi V., Pharm. Chem., 2 (2010), 63.

[42] Santhanamoorthi N., Lo C., Jiang J., J. Phys. Chem. Lett., 4 (2013), 524.

[43] De Angelis F., FAntacci S., Selloni A., Nanotechnology, 19 (2008), 424002.

[44] Granovsky A.A., PC Gamess/Firefly version 7.1 $G$, http://classic.chem.msu.su/gran/Gamess/ index.

[45] Bazargan M.H., Malekshahi Byranvand M., Kharat A.N., Chalcogenide Lett., 7 (2010), 515.

[46] Huang Z., Liu X., Li K., Li D., LuO Y., Li H., Song W., Chen L., Meng Q., Electrochem. Commun., 9 (2007), 596.

[47] Abdel-Latif M.S., Abuiriban M.B., El-Agez T.M., TAYA S.A., Int. J. Renew. Energ. Res., 5 (2015), 294.

[48] Ma T., Inoue K., Noma H., Yao K., Abe E., J. Photoch. Photobiol. A, 152 (2002), 207.

[49] Allouche A.-R., Gabedit, Version 2.1.8; 2007.

[50] Khadtare S.S., Ware A.P., Salunke-GaWali S., JadKar S.R., Pingale S.S., PAThan H.M., RSC Adv. 5 (2015), 17647.
[51] Song J., XU J., B. Korean Chem. Soc., 34 (2013), 3211

[52] Wang X., Wang L., Wang Z., Wang Y., TAmai N., Hong Z., Kido J., J. Phys. Chem. C, 117 (2013), 804.

[53] Eithiraj R.D., Geethalakshmi K.R., Chem. Phys. Lett., 585 (2013), 138.

[54] Radwan I.M., Taya S.A., El-Agez T.M., AbdelLatif M.S., Ghamri H.S., Acta Phys. Pol. A, 130 (2016), 795.

[55] Anand M., Suresh S., Adv. Nat. Sci. Nanosci. Nanotechnol., 6 (2015), 035008.

[56] LiU J., LiU B., TAng Y., Zhang W., Wu W., Xie Y., Zhu W., J. Mater. Chem. C, 3 (2015), 11144.

[57] Batnisi A., Abdel-Latif M.S., El-Agez T.M., Taya S.A., Ghamri H., J. Theor. Appl. Phys., 10 (2016), 265.

[58] Taya S.A., El-Agez T.M., Abdel-Latif M.S., Ghamri H., BAtniJi A., TABAZA W.A., J. Nanoelectron. Phys., 8 (2016), 01026.

[59] Zhang X., Chen L., Li X., Mao J., Wu W., Ågren H., HuA J., J. Mater. Chem. C, 2 (2014), 4063.

[60] Iraj M., Kolahdouz M., Asl-Soleimani E., EsMaili E., Kolahdouz Z., J. Mater. Sci. Mater. El., 27 (2016), 6496. 